\title{
Risk factors and functional outcomes of surgical treatment of fall-related hip fractures in patients with Parkinson's disease
}

\begin{abstract}
Purpose: One of the cardinal symptoms of Parkinson's disease (PD) is represented by postural instability and disturbed balance which can cause frequent falls in these patients. Indeed, the increased risk of falling in combination with osteoporosis puts PD patients at high risk for hip osteoporotic fractures. This study was aimed to evaluate the potential risk factors associated with fall-related hip fracture in individual with PD and 2) to determine the impact of the disease on the perioperative course and functional outcome of these fractures.
\end{abstract}

Materials and methods: From 2005 to 2016, 209 patients (98 males and 111 females, aged $>65$ years) with a definitive diagnosis of idiopathic parkinsonism were enrolled in this multicenter retrospective study. From these patients, 123 sustained falling, while 86 did not. From the patients who sustained a fall, 41 patients sustained a hip fracture and were surgically treated with either internal fixation or hip hemiarthroplasty. The recorded clinical features were age, disease duration, falls, and type fracture. The risk of fall was assessed by Morse fall scale. According to the scores of the Unified Parkinson's Disease Rating Scale (UPDRS) and the Hoehn and Yahr staging(H\&Y) we graded the PD severity. Osteoporosis was diagnosed using bone mineral density (BMD). The pre-fracture Barthel Index (BI) and Timed Up and Go test (TUG) were used to assess the functional status. In order to compare parameters that determine the functional result, was included a reference group of 40 , sexand age-matched, patients. This group comprised of individuals without intake of anti-parkinson medication. The perioperative complications and the inhospital mortality were both reported.

Results: The mean follow-up was 24-months. In this study, the percentage of falls was $58.8 \%$, while the percentage of osteoporosis between patients with and without falls were respectively $33.3 \%$ (42/123) and $15.4 \%$ (13/86). 74 patients had fall-related fractures. Statistical analysis of the clinical manifestations and functional score findings between the PD patients with fall-related fractures and PD patients without fracture, revealed that sex $(p=0.001)$, mean Morse fall scale $(p<0.0001)$ and Hoehn and Yahr stage $(p=0.009)$ were significant variables. Regarding the functional outcome, no significant differences were observed between the groups [BI $(p=0.21)$ and TUG $(p=0.89)]$. At the final follow-up, in patients with PD who were surgically treated for a fall-related hip fracture compare to patients without $\mathrm{PD}$, the functional outcome was
Volume 10 Issue 2 - 2020

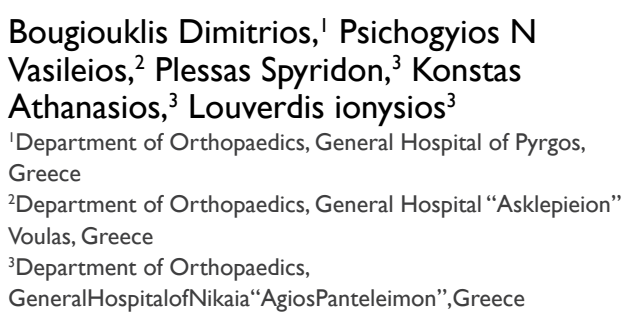

Correspondence: Bougiouklis Dimitrios MD, Orthopeadic Surgeon, Orthopaedics Department of General Hospital of Pyrgos, Syntriada Pyrgos, Greece, Tel 003026210 82706, 0030 2623 401671,0030699 3390492,Email dimmed@hotmail.com

Received: October 28, 2019 | Published: April 24, 2020

reduced according to Barthel Index $(\mathrm{p}=0.001)$. Urinary tract infection was the more frequent perioperative complication. Post-operative pneumonia is another frequent complication, occurred in $5.5 \%$ of our series. 8 of 41 patients developed a pressure sore, while 1 patient with femoral neck fracture suffered a dislocation and underwent revision surgery. The mean length of hospital stay for Parkinson's disease patients was 14 days, while patients without PD were staying 9 days. The in-hospital mortality rate for all patients was $4.3 \%$.

Conclusions: Female sex, and advanced stage of PD and a higher mean Morse fall scale are associated with higher risk of fall-related hip fractures. Patients with PD who suffered a hip fracture are inclined to a longer hospital stay and a higher risk of complications. However, Parkinson's disease does not represent a risk factor for a higher mortality or an inferior functional result, but in these patients, after 2-years follow-up, the functional outcome was reduced according to Barthel Index.

Keywords: parkinson's disease, fall-related fracture, hip fracture, complication, functional outcome
Abbreviations: PD, parkinson disease; UPDRS, unified parkinson's disease rating scale; MFS, morse fall scale; H\&Y, hoehn and yahr staging; BMD, bone mineral density, FRAX, fracture risk assessment tool; BI, barthel index; TT, tinetti test; TUG,timed up and go test

\section{Introduction}

Parkinson's disease (PD) is a common degenerative disorder of central nervous system, characterized by cellular death in substantia nigra, which leads to deficiency of dopamine in the midbrain ${ }^{1}$ The principal symptoms of PD are represented by tremor, movement slowness, postural instability and rigidity, resulting in disturbed balance and difficulty in walking. These symptoms increase the risk of falling. ${ }^{2,3}$ Actually, falls is the most frequent reason for hospital admission in these patients. ${ }^{4}$ Furthermore, PD and especially in the advanced stages (Hoehn and Yahr stages III and IV) is accompanied by deficiency of vitamin $\mathrm{D}$, which one in combination with reduced mobility and female sex causes osteopenia and osteoporosis. ${ }^{5}$

The increased incidence of falls in combination with osteoporosis leads to a high rate of osteoporotic fractures. ${ }^{6,7}$ Among these, vertebral and femoral fractures are the most frequent. ${ }^{8,9}$ In elderly people, hip fractures are related with high morbidity mortality and high health costs. ${ }^{10,11}$ Many studies have indicated that patients with PD have a 2.5- to 4-fold increased risk of hip femoral fractures in comparison with age- and sex-matched normal individuals. ${ }^{12}$

According to a prospective fracture database, Parkinson's disease patients, had a longer stay in the hospital and presented a lower mobility compared to patients without PD. ${ }^{13}$ On the other hand, in literature can someone meet retrospective studies conducted at university teaching 
hospitals on patients with PD who underwent a hemiarthroplasty for femoral neck fractures, which showed that PD had not significant influence on the outcome. ${ }^{14,15}$ Because of these conflicting results, there is still a discussion if PD influences the perioperative course and functional outcome of surgical treatment of hip fractures.

The aim of this study was 1) to evaluate the potential risk factors associated with fall-related hip fracture in individual with PD and 2) to determine the impact of the disease on the perioperative course and functional outcome of these fractures.

\section{Materials and methods}

From 2005 to 2016, 209 patients (aged >65 years) with a definitive diagnosis of idiopathic PD were enrolled in this multicenter retrospective study. Individuals defined as patients with an idiopathic $\mathrm{PD}$, were all those who were receiving a daily steady dose of antiparkinsonian drugsduring the two last years. Exclusion criteria were the presence of symptoms of dementia, other pyramidal signs, ataxia, motor weakness caused by disuse of the lower limbs, severe sensorialimpairment and severe vision problems related with balance. Anyone with a malignancy-associated fracture was also excluded from the study (Table 1).

Table I Inclusion and exclusion criteria from the study.

\begin{tabular}{ll}
\hline Inclusion criteria & Exclusion criteria \\
\hline $\begin{array}{l}\text { Definitive diagnosis of Parkinson's } \\
\text { disease (taking a daily steady dose } \\
\text { of antiparkinsonian medication } \\
\text { during the two last years). }\end{array}$ & Symptoms of dementia. \\
& Other pyramidal signs \\
& -Ataxia \\
& - Disuse of lower limbs that cause \\
& motor weakness \\
& Sensorial impairment \\
& - Vision problems that may \\
& compromise the balance \\
& - Presence of a malignancy-associated \\
fracture.
\end{tabular}

The 209 patients with idiopathic PD included 98 males (mean age 73.3 years) and 111 females (mean age, 73.9 years). From the 209 patients, 123 sustained a fall, while 86 did not. From the patients who experienced falling, 41 patients sustained a hip fracture and were surgically treated with either internal fixation or hip arthroplasty (Table 2).

The recorded clinical features were age, disease duration, falls, and type fracture. The risk of fall was assessed by Morse fall scale (MFS). ${ }^{16}$ The residential status was defined as living alone or with family members or residing in a penitentiary. As a marker for severe functional impairment we used the need of more than one hour and half of daily assistance with basic activities. According to the scores of the Unified Parkinson's Disease Rating Scale (UPDRS) and the Hoehn and Yahr staging (H\&Y) we graded the PD severity(Table 2). ${ }^{17,18} \mathrm{We}$ measured bone mineral density (BMD) using dual energy $x$-ray absorptiometry in the spine and femoral neck regions. Osteoporosis was defined as spinal BMD $>2.5$ SD below the average value in a young person, i.e. a T-score $\leq-2.5 \mathrm{SD} .{ }^{19}$ The pre-fracture Barthel Index (BI) ${ }^{20}$ and Timed Up and Go test (TUG) $)^{21}$ were used to assess the functional status. The perioperative complications and the in-hospital mortality were both reported.

Table 2 General information of patients

$\begin{array}{ll}\cdot \text { Total (number of patients) } & 209 \\ \text { Men (mean age) } & 98 \text { (73.3 years) } \\ \text { Women (mean age) } & 11 \text { I (73.9 years) }\end{array}$

\section{- Hoehn and Yahr staging}

Stage I

Stage II

Stage III

86

Stage IV

Stage $V$

- History of falling

Number of patients who sustained a fall

Number of patients who did not sustain a fall

86

- Fall-related hip fractures

\section{- Type of fall-related hip fractures}

Femoral neck

Intertrochanteric

Subtrochanteric

6

\section{- Surgical treatment of fall-related hip fractures}

Internal fixation

Hip arthroplasty

\section{-Pre-fracture residenctial status}

Living alone (n. of patients)

Living with family membres (n. of patients)

Living in a penitentiary (n. of patients)

\section{- Severe functional impairment (pre-} operatively)

Patients with care need 42

Patients witout care need 167

In order to compare parameters that determine the functional result of surgical treatment of fall-related hip fractures, in this study was included a reference group of 40, sex- and age-matched, patients. The reference group was comprised by individuals with no intake of antiparkinson medication.

Regarding the statistic method, an unpaired Student's t test was 
used to compare the effect of individual variables including age, mean functional score on fracture, underlying diseases, levodopa equivalent dose and length of hospital stay. A Fisher's exact test was used to evaluate the differences of the categorical variables (gender distribution, type of surgery, mortality rate and the occurrence of complications). A Chi-square test was conducted to determine the distribution of the various fracture types. A multivariate linear regression analysis including the co-variables which influences patient outcome after femoral fracture, was performed to further assess the influence of PD on the outcome. For all tests, significance was assumed at $\mathrm{p}<0.05$.

\section{Results}

The mean follow-up was 24-months (average between 2 and 4.5 years). A higher proportional of patients suffering with moderate to severe symptoms (H\&Y stage III and IV $62.6 \%$ ). Levodopa either alone or in combination (85\%) was the commonest prescribed medication. Only $1.5 \%$ of patients received dopamine agonists alone and $8.5 \%$ in combination with other agents. In our study, we did not observe any statistically significant difference in the increased risk of falling between patients that received levodopa alone and those who received a combination of dopamine agonist and levodopa. We also did not notice any statistical correlation between the increased risk of falls and the duration of treatment, but we observed an increased risk immediately after initiation of the antiparkinsonian drugs. Patients who used dopaminergic drugsand antidepressants had a 2-fold increased risk of falling. Finally, the high doses of dopaminergic drugs were statistically correlated with the high risk fall.

In this study, the percentage of falls was $58.8 \%$, while the percentage of osteoporosis between patients with and without falls were respectively $33.3 \%(42 / 123)$ and $15.4 \%$ (13/86) (Table 3). Seventy-four patients had fall-related fractures. Of these patients, forty-one had a hip fracture, twenty-five had a spine fracture, four a wrist fracture, three of them an ankle fracture and finally one had a face fracture.

Table 3 Correlation between osteoporosis and risk of fall

\begin{tabular}{lll}
\hline & PD-patients who sustained a fall $(\mathbf{n}=\mathbf{I} 23)$ & PD-patients who not-sustained a fall $(\mathbf{n}=\mathbf{8 6})$ \\
\hline Percentage of osteoporosis & $33.3 \%(42 / I 23)$ & $15.4 \%(13 / 86)$
\end{tabular}

Statistical analysis of the clinical manifestations and functional score findings between the PD patients with fall-related fractures and PD patients without fracture, revealed that $\operatorname{sex}(p=0.001)$, mean Morse fall scale $(\mathrm{p}<0.0001)$ and Hoehn and Yahr stage $(\mathrm{p}=$ 0.009 ) were significant variables. However, after a multiple logistic regression analysis only sex and mean Morse fall scale remained independently associated with fall related fracture. No significant differences were found in the mean Barthel Index $(p=0.049)$, presence of comorbidities $(\mathrm{p}=0.039)$ and residential status $(\mathrm{p}=0.7)($ Table 4$)$.

The period of time from hospital admission to surgery $(p=0.75)$ and the type of surgery (internal fixation or hemiarthoplasty, $p=$ 0.61 ) did not influence the perioperative clinical course. Regarding the functional outcome at discharge, no significant differences were observed between patients with PD who sustained a fall-related fracture and the control group (sex- and age-matched patients without PD who sustained a fall-related fracture), ( $p$ of Barthel Index equal to 0.21 and $p$ of TUG equal to 0.89 ). At the final follow-up, according to Barthel Index, the functional ability of the patients with PD who were surgically treated for a fall-related hip fracture was reduced $(\mathrm{p}=$ 0.001) compared to that of the patients without PD (Table 5).

Regarding the perioperative complication, urinary tract infections account for $90 \%$ of all complications. Post-operative pneumonia is another frequent complication, occurred in $5.5 \%$ of our series. 8 of 41 patients developed a pressure sore, while 1 patient with femoral neck fracture suffered a dislocation and underwent revision surgery. The mean length of hospital stay for Parkinson's disease patients was 11 days, while patients without PD were staying 9 days. The in-hospital mortality rate for all patients was $4.3 \%$.

Table 4 Risk factors associated with fall-related fractures

\begin{tabular}{|c|c|c|c|c|}
\hline & $\begin{array}{l}\text { PD-patients } \\
\text { with fall-related } \\
\text { fracture }(n=44)\end{array}$ & $\begin{array}{l}\text { PD-patients } \\
\text { without fall-related } \\
\text { fracture }(n=79)\end{array}$ & Odds ratio & P Value \\
\hline Age (years) & 73.1 & 71.7 & & \\
\hline Sex (men/women) & $11 / 33$ & $45 / 34$ & 1.04 & 0.14 \\
\hline Duration of PD (years) & 4.83 .5 & $4.2 \pm 3.7$ & 4.61 & 0.001 \\
\hline Hoehn and Yahr stage & & & 1.03 & 0.51 \\
\hline I & 7 & 15 & & \\
\hline II & 3 & 31 & & \\
\hline IV & 14 & 8 & & \\
\hline
\end{tabular}


Table Continued

\begin{tabular}{|c|c|c|c|c|}
\hline & $\begin{array}{l}\text { PD-patients } \\
\text { with fall-related } \\
\text { fracture }(n=44)\end{array}$ & $\begin{array}{l}\text { PD-patients } \\
\text { without fall-related } \\
\text { fracture }(n=79)\end{array}$ & Odds ratio & P Value \\
\hline V & 2 & 5 & & \\
\hline Morse fall scale & $82 \pm 21$ & $53 \pm 29$ & 1.02 & $<0.001$ \\
\hline Mean Barthel index & $66 \pm 18$ & $67 \pm 35$ & 1.33 & 0.049 \\
\hline $\begin{array}{l}\text { Comorbidities (heart disease, hypertension, diabetes, renal } \\
\text { disease, osteoasrthitis) }\end{array}$ & 4I patients & 75 patients & 1.3 & 0.039 \\
\hline Residencial status & & & 1.25 & 0.7 \\
\hline living alone or with family members & 35 patients & 67 patients & & \\
\hline
\end{tabular}

Table 5 Post-operative clinical course and functional outcome for patients with and without PD who were treated surgically for a fall-related hip fracture

\begin{tabular}{llll}
\hline & $\begin{array}{l}\text { Patients with PD who } \\
\text { sustained a fall-related hip } \\
\text { fracture }\end{array}$ & $\begin{array}{l}\text { Patients without PD who } \\
\text { sustained a fall-related hip } \\
\text { fracture }\end{array}$ & P value \\
\hline Length of hospital (days) & II & 9 & 0.035 \\
Functional outcome at discharge & $51 \pm 25$ & 0.21 \\
BI at discharge & $40 \pm 75$ & $40 \pm 10$ & 0.89 \\
TUG at discharge (s) & $39 \pm 85$ & & 0.001 \\
$\begin{array}{l}\text { Functional outcome at the } \\
\text { final follow-up }\end{array}$ & $44 \pm 53$ & $70 \pm 62$ & $0.1 \mathrm{I}$ \\
BI & $35 \pm 15$ & $30 \pm 42$ & \\
\hline TUG (s) & & & \\
\hline
\end{tabular}

\section{Discussion}

This study was aimed to determine the frequency of falling, the risk factors of fall-related hip fractures in patients with PD and to evaluate the impact of Parkinson disease on the functional outcome of surgical treatment of these fractures. In other studies, the frequency of falls and fall-related fracture in patients with PD are estimated to be respectively $51 \%-87 \%$ and $17 \%-59 \% .{ }^{22,23}$ In our study, the frequency of falls and fall-related fracture in patients with PD is respectively 123 out of 209 (58.8\%) and 74 out of 209 (35.4\%). Sex and mean Morse fall scale represented two main risk factors which were independently associated with fall-related fractures. Actually, there were three times more females with fall-related hip fracture than males.

According to Yiannopoulou et al., ${ }^{24}$ who compared, with agematched controls, hip fracture patients, Parkinson's disease is an independent risk factor for hip fractures and must be considered as an independent predictor in fracture risk calculators (e.g. the Qfracture tool). ${ }^{25}$ Furthermore, Shribman et al. ${ }^{26}$ recommended the use of FRAX to assess fall-related fracture riskin patients with PD who had fallen or are using walking aids or who have already suffered a previous fragility fracture. Lyell et al. ${ }^{27}$ assessing in patients with PD the age, the number of previous falls and possible fractures, the Calcium and
Vitamin D deficiency and the Qfracture score, recommended that all women aged $\geq 75$ years and men aged $\geq 80$ years with Parkinson's disease, as also all women aged $\geq 70$ and men aged $\geq 75$ with past history of falls, should be prescribed bone protection. Indeed, in highrisk patients with PD, especially in females with mean Morse fall scale higher to 72.5 , prevention of osteoporosis is considered to be necessary.

In many studies, the incidence of hip fractures in Parkinson's disease patients is certainly higher in people with Parkinson's disease compared with individuals without PD. In fact, Chen et al. ${ }^{28}$ observed a twice higher frequency of hip fractures in PD patients than in a control group (10.4 versus $4.1 \%$, respectively) during their 8 -year study period. Benzinger et al. ${ }^{29}$ found the fracture risk to be higher in the male patients, while Melton et al. ${ }^{9}$ supported that this risk is higher in females with dementia. In addition, according to other studies, the intake of dopaminergic agents and consequently, the high levels of homocysteine are increased until twice the risk of hip fractures. ${ }^{30,31}$ On the other hand, in advanced stages of Parkinson's disease the worsening of postural instability causes an increased tendency of falling. Actually, in this study, disease severity (Hoehn and Yahr stage III and IV) and higher mean Morse fall scale represented independent risk factors for fall-related hip fractures. Furthermore, the incidence of 
these fractures was reduced in patients with a physiotherapy assistance aimed at improving balance.

Concerning the morphology of fall-related hip fracture, in our study out a total of 41 fractures, 25 were cervical (intracapsular) fractures (Figure 1), 13 were intertrochanteric (extracapsular) fractures Figure 2 and 3 were sub-trochanteric fractures (Figure 3). In agreement with these results, Fisher et al. ${ }^{32}$ in their study reported femoral neck fractures to be commoner than intertrochanteric fractures in Parkinson's disease patients (6.3 vs. $1.6 \%, \mathrm{p}=0.002$ ).

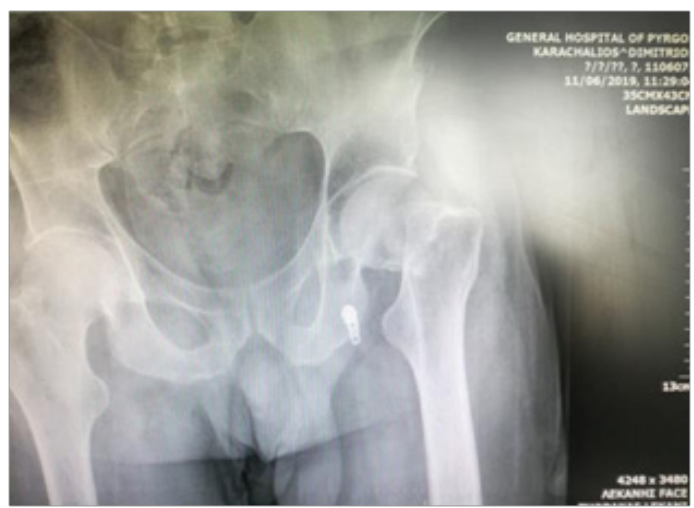

Figure I 68-year old male PD patients with cervical femur fracture of his left hip. The fall happened in an institute. This patient was also receiving antipsychotic medication.

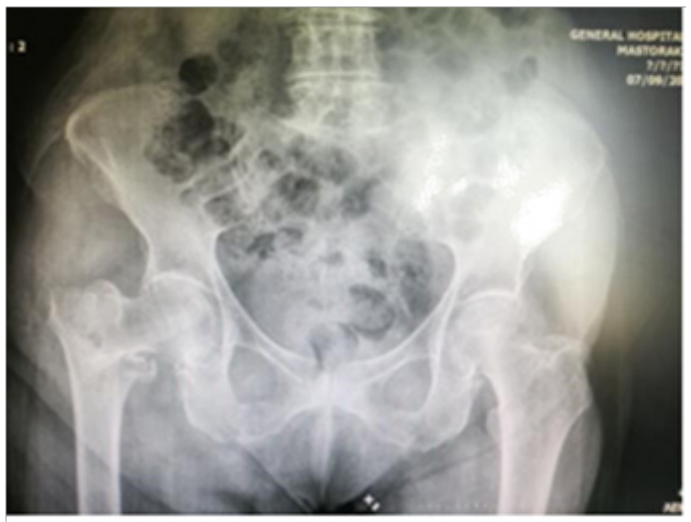

Figure 2 84-year old female PD patient with intertrochanteric fracture of her right hip, after fall in her house.

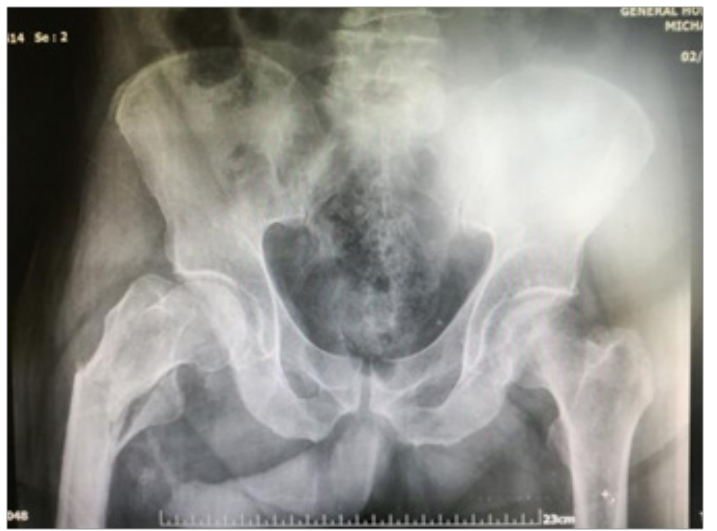

Figure 3 86-year old male PD patient with sub-trochanteric fracture of his right hip, after fall from own height.
In this study, the time spent from hospital admission to surgery $(p=0.75)$ and the type of surgical technique (internal fixation or hemiarthroplasty, $p=0.61$ ) did not influence the perioperative course, in contrast with the existed debate in literature. The studies of Coughlin and Templeton ${ }^{33}$ and Turcotte et al. ${ }^{34}$ described a significantly higher rate of mortality, post-operative complications and worse functional outcome in patients treated with hemiarthroplasty than in those treated with internal fixation (Figure 4-6). On the other hand, Templeton and Turcotte et al. ${ }^{34}$ Eventov et al..$^{35}$ and Staeheli et al. ${ }^{36}$ consider that in these patients, hemiarthoplasty is the preferred method with satisfactory functional outcomes, despite the higher risk of mortality. In this study, at the time of discharge no differences were observed between patients with PD and those without PD, regarding the postoperative functional outcome of the surgical treatment of fallrelated hip fractures. These findings agree with the study of Yuasa et al. ${ }^{37}$ in which the postoperative walking ability of patients with PD was comparable to the one of the control group. In contrast to these results Walker et al. ${ }^{13}$ observed that patients with PD were more likely to be limited to a bed. These conflicting results can be explained by the longer hospital stay of patients with PD compared with those without PD.

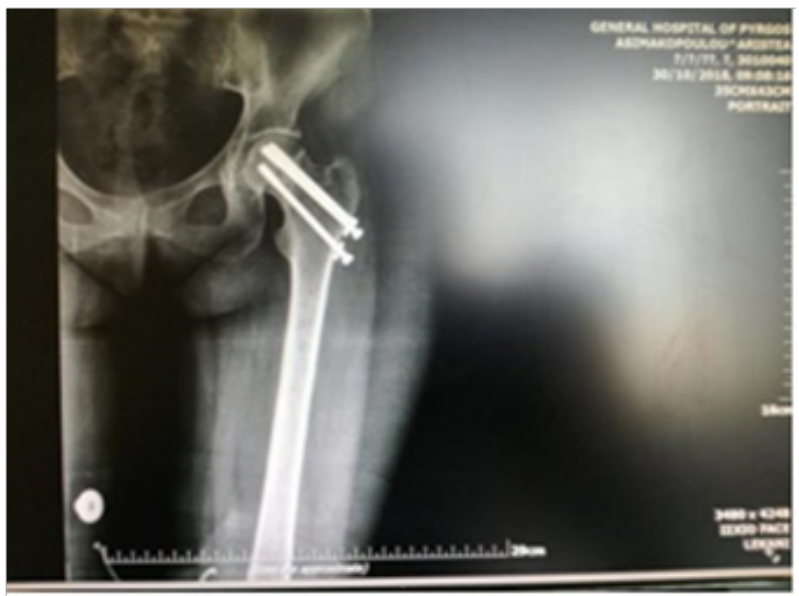

Figure 4 Female's PD patient post-operative $X$-ray, after 5 months from the surgical treatment with internal fixation of the cervical fracture of her left hip.

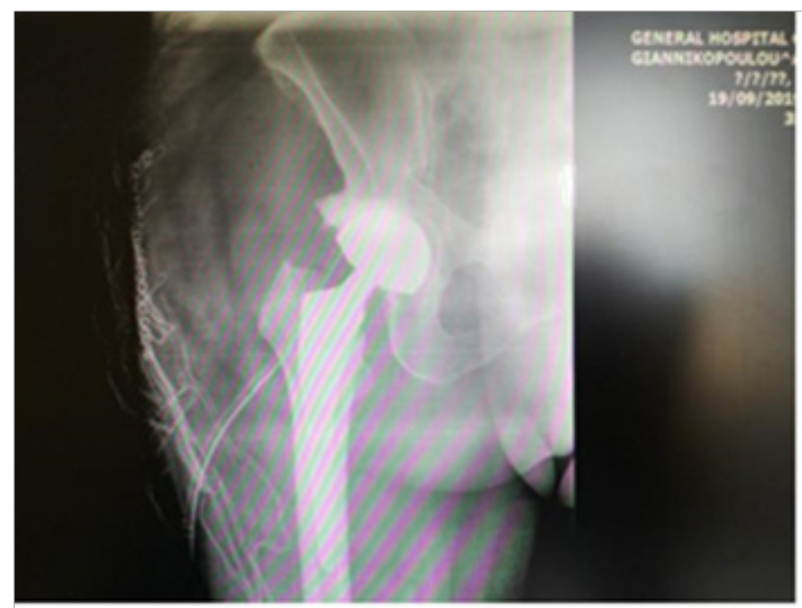

Figure 5 Female's PD patient immediate post-operative $X$-ray, from the surgical treatment with hemiarthroplasty of the fall-related cervical fracture of her right hip. 


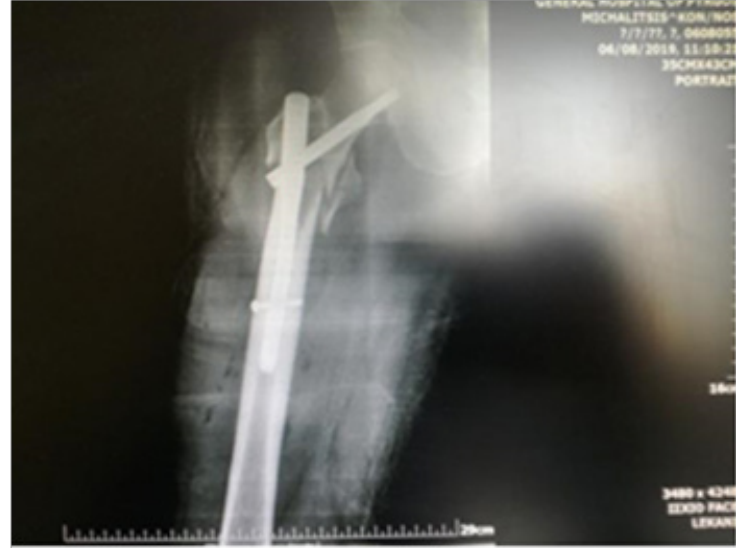

Figure 6 Male's PD patient post-operative X-ray, after 40days from the surgical treatment with intramedullary nailing of the sub-trochanteric fracture of her right hip. This patient had fallen down the steps of the Church.

Therefore, we must take note that both patients with and without PD can achieve the same final functional outcome; however, patients with PD need a more intensive physiotherapeutic mobilization program. Concerning the perioperative complications, in this study, urinary tract infection was the commonest complication. It can be explained by the dysfunction of bladder due topost-micturitional residual urine ${ }^{38}$ and by the prolonging stay of urinary catheters. Furthermore, patients with parkinsonism have frequent atelectasis and consequently the retention of secretions leads to pulmonary infection. Indeed, pneumonia is the main cause of death in Parkinson's disease patients such in the community as in the hospital. ${ }^{39}$ According to Yuasa et al, pneumonia occurred in $8.6 \%$ of Parkinson's disease patients with fractures, compared with $1.2 \%$ in those of control group. Then, it is obvious that respiratory exercises and early mobilization are essential in these patients. Also, in this study, 8 of 41 patients developed a pressure sore, while 1 patient with femoral neck fracture suffered a dislocation and underwent revision surgery. In the development of pressure sores immobility, low skin turgor and reduced muscle mass play a crucial role. ${ }^{40,41}$ Walker et al.'s, reported a pressure sores percentage equal to $13.8 \%$ in patients with parkinsonism who underwent surgery due to hip fracture, compared with only $3.1 \%$ in those of control group $(\mathrm{p}=0.001)$. Another potential complication in PD patients, who underwent hemiarthroplasty for acervical hip fracture, is represented by dislocation. In the study of Turcotte et al., ${ }^{42}$ it is described a percentage of $10.6 \%$ in a series of forty-seven posterior-approach hemiarthroplasties. Accordingto Whittacker et al. ${ }^{43}$ and Hammer, ${ }^{44}$ the rate of re-operation was four times higher in patients PD who suffered hip fractures compared to those of control group (6.9 vs. $1.7 \%, \mathrm{P}$ $=0.4$ ). In addition, Karadsheh et $\mathrm{al}^{45}$ have reported higher rates of revision surgery in their series.

Other complications which were found to be increased in patients with parkinsonism are renal failure, myocardial infarctions and ischemic cardiac disease. For these reasons, patients with Parkinson's disease suffering femoral fractures must be considered as a particularly vulnerable patient category. Finally, there is still a debate regarding the mortality following hip fractures in patients with PD. While some studies reported a similar 1-year mortality to nonParkinson'sdisease patients45, others have mentioned a higher rate of mortality. In fact, Wieler et al. ${ }^{46}$ and Harris-Hayes et al.47 observed an increased percentage of mortality in PD patients suffering hip fracture compared with those of control group.

\section{Conclusion}

There is a five times higher risk of fall-related hip fracture in patients with parkinsonism in relation with age- and sex-matched controls. This risk is proportional with the stage of disease. For this reason, further researches are necessary in order to prevent the falls and to improve the balance in these patients. In this study, Parkinson's disease does not represent a risk factor for a higher mortality or an inferior functional result. However, these patients are inclined to a longer hospital stay and a higher risk of complications. The collaboration of various specialties is of essential importance in order to reduce the days spent in hospital and increase the probability to achieve the former movement ability. Finally, the prevention of osteoporosis is important to attain the best final result.

\section{Acknowledgments}

None.

\section{Conflicts of interest}

The author declares no conflict of interest.

\section{References}

1. Van der Schyf CJ, Geldenhuys WJ. Multi-modal drugs and their future for Alzheimer's and Parkinson's disease. Int Rev Neurobiol. 2011;100:107e25.

2. Balash Y, Peretz C, Leibovich G, Herman T, et al. Falls in outpatients with Parkinson's disease: frequency, impact and identifying factors. $J$ Neurol. 2005;252:1310-1315.

3. Hely MA, Reid WG, Adena MA, et al. The Sydney multicenter study of Parkinson's disease: the inevitability of dementia at 20 years. Mov Disord. 2008;23(6):837-844.

4. Temlett JA, Thompson PD. Reasons for admission to hospital for Parkinson's disease. Intern Med J. 2006;36(8):524-526.

5. Invernizzi M, Carda S, Viscontini GS, et al. Osteoporosis in Parkinson's disease. Parkinsonism Relat Disord. 2009;15(5):339e46.

6. Van den Bos F, Speelman AD, Samson M, et al. Parkinson's disease and osteoporosis. Age Ageing. 2013;42(2):156-162.

7. Fink HA, Kuskowski MA, Taylor BC, et al. Association of Parkinson's disease with accelerated bone loss, fractures and mortality in older men: the Osteoporotic Fractures in Men (MrOS) study. Osteoporos Int. 2008;19:1277-1282.

8. Vestergaard P, Rejnmark L, Mosekilde L. Fracture risk associated with parkinsonism and anti-Parkinson drugs. Calcif Tissue Int. 2007;81(3):153-161.

9. Melton LJ, Leibson CL, Achenbach SJ, et al. Fracture risk after the diagnosis of Parkinson's disease: Influence of concomitant dementia. Mov Disord. 2006;21:1361-1367.

10. Ioannidis G, Papaioannou A, Hopman WM, et al. Relation between fractures and mortality: results from the Canadian Multicentre Osteoporosis Study. CMAJ. 2009;181(5):265-271.

11. Johnell O, Kanis JA. An estimate of the worldwide prevalence and disability associated with osteoporotic fractures. Osteoporos Int. 2006;17(12):1726-1733.

12. Bhattacharya RK, Dubinsky RM, Lai SM, et al. Is there an increased risk of hip fracture in Parkinson's disease? A nationwide inpatient sample. Mov Disord. 2012.27(11):1440-1443.

13. Walker RW, Chaplin A, Hancock RL, et al. Hip fractures in people with 
idiopathic Parkinson's disease: incidence and outcomes. Mov Disord 2013;28(3):334-340.

14. Idjadi JA, Aharonoff GB, Su H, et al. Hip fracture outcomes in patients with Parkinson's disease. Am J Orthop (Belle Mead NJ). 2005;34(7):341346.

15. Clubb VJ, Clubb SE, Buckley S. Parkinson's disease patients who fracture their neck of femur: a review of outcome data. Injury. 2006;37(10):929934.

16. O'Connell B, Myers $\mathrm{H}$. The sensitivity and specificity of the morse fall scale in an acute care setting. J Clin Nurs. 2002;11:134e6.

17. Martínez-Martín P, Gil-Nagel A, Gracia LM, et al. Unified Parkinson's disease rating scale characteristics and structure. The Cooperative Multicentric Group. Mov Disord 1994;9(1):76e83.

18. Hoehn MM, Yahr MD. Parkinsonism: onset, progression and mortality. Neurology. 1967;17(5)d:427e 42.

19. Lane JM, Serota AC, Raphael B. Osteoporosis: differences and similarities in male and female patients. Orthop Clin North Am. 2006;37(4):601e 9.

20. Lubke N, Meinck M, Von Renteln-Kruse W. The Barthel Index in geriatrics. A context analysis for the Hamburg Classification Manual. Z Gerontol Geriatr. 2004;37(4):316-326.

21. Podsiadlo D, Richardson S. The timed "Up \& Go": a test of basic functional mobility for frail elderly persons. $J$ Am Geriatr Soc. 1991;39(2):142-148

22. Wood BH, Bilclough JA, Bowron A, et al. Incidence and prediction of falls in Parkinson's disease: a prospective multi-disciplinary study. $J$ Neurol Neurosurg Psychiatr. 2002;72:721e5.

23. Matinolli M, Korpelainen JT, Korpelainen R, et al. Mobility and balance in Parkinson's disease: a population based study. Eur J Neurol. 2009;16(1):105e11.

24. Yiannopoulou KG, Papageorgiou SG, Anastasiou IP, et al. Prevalence of Parkinsonism in older patients with hip fracture. Hip Int. 2011;21(3):351355

25. Hippisley-Cox J, Coupland C. Derivation and validation of updated QFracture algorithm to predict risk of osteoporotic fracture in primary care in the United Kingdom: prospective open cohort study. BMJ. 2012;344:e3427.

26. Shribman S, Torsney KM, Noyce AJ, et al. A service development study of the assessment and management of fracture risk in Parkinson's disease. J Neurol. 2014;261(16):1153-1159.

27. Lyell V, Henderson E, Devine M, et al. Assessment and management of fracture risk in patients with Parkinson's disease. Age Ageing. 2015;44(1):34-41

28. Chen YY, Cheng PY, Wu SL, et al. Parkinson's disease and risk of hip fracture: an 8-year follow-up study in Taiwan. Park Relat Disord. 2012;18(5):506-509.

29. Benzinger P, Rapp K, Maetzler W, et al. Risk for femoral fractures in Parkinson's disease patients with and without severe functional impairment. PLoSONE. 2014;9(5):e97073.

30. Arbouw MEL, Movig KLL, van Staa TP, et al. Dopaminergic drugs and the risk of hip or femur fracture: a population-based case-control study. Osteoporos Int. 2011;22(7):2197-2204.
31. Sato Y, Iwamoto J, Kanoko T, et al. Homocysteine as a predictive factor for hip fracture in elderly women with Parkinson's disease. Am J Med. 2005;118(11):1250-1255.

32. Fisher A, Srikusalanukul W, Davis MW, et al. Clinical profiles and risk factors for outcomes in older patients with cervical and trochanteric hip fracture: similarities and differences. J Trauma Manag Outcomes. $2012 ; 6: 2$.

33. Coughlin L, Templeton J. Hip fractures in patients with Parkinson's disease. Clin Orthop. 1980;148:192-195.

34. Turcotte R, Godin C, Duchesne R, et al. Hip fractures and Parkinson's disease. A clinical review of 94 fractures treated surgically. Clin Orthop. 1990;256:132-136

35. Eventov I, Moreno M, Gellar E, et al. Hip fractures in Parkinson's syndrome. J Trauma. 1983;2(23):98-101.

36. Staeheli JW, Frassica FJ, Franklin H. Prosthetic replacement of the femoral head for fracture of the femoral neck in patients who have Parkinson disease. J Bone Joint Surg Am. 1988;704(4):565-568.

37. Yuasa T, Maezawa K, Nozawa M, et al. Surgical outcome for hip fractures in patients with and without Parkinson's disease. J Orthop Surg (Hong Kong). 2013;21(2):151-153.

38. Winge K, Nielsen KK. Bladder dysfunction in advanced Parkinson's disease. Neurourol Urodyn. 2012;31(8):1279-1283.

39. Lethbridge L, Johnston GM, Turnbull G. Co-morbidities of persons dying of Parkinson's disease. Prog Palliat Care. 2013;21(3):140-145.

40. Spector WD. Correlates of pressure sores in nursing homes: evidence from the National Medical Expenditure Survey. J Invest Dermatol. 1994;102(6):42S-5S

41. Margolis DS, Knauss J, Bilker W, et al. Medical conditions as risk factors for pressure ulcers in an outpatient setting. Age Ageing. 2003;32(3):259-

42. Turcotte R, Godin C, Duchesne R, et al. Hip fractures and Parkinson's disease. A clinical review of 94 fractures treated surgically. Clin Orthop Relat Res. 1990;256:132-136.

43. Whittacker R, Abeshaus M, Scholl H, et al. Fifteen years' experience with metallic endoprosthetic replacement of the femoral head for femoral neck fractures. J Trauman. 1972;12(9):799-806.

44. Hammer AJ. Intertrochanteric and femoral neck fractures' in patients with parkinsonism. S Afr Med J. 1991;79:1990-1992.

45. Karadsheh M, Lucas R, Morgan J, et al. Mortality and Revision Surgery Are Increased in Patients With Parkinson's Disease and Fractures of the Femoral Neck. Clin Orthop Relat Res. 2015;473(10):3272-3279.

46. Wieler M, Jones CA, Martin WRW, et al. Incidence of hip fracture in Parkinson disease: a population-based study in British Columbia Canada. Parkinsonism Relat Disord. 2014;15:S74.

47. Harris-Hayes M, Willis AW, Klein SE, et al. Relative mortality in U.S. Medicare beneficiaries with Parkinson disease and hip and pelvic fractures. J Bone Joint Surg Am. 2014;96(4):e27. 